\title{
How Does Supervisor Burnout Affect Leader-Member Exchange? A Dyadic Perspective
}

\author{
Cody Logan Chullen, East Carolina University, USA
}

\begin{abstract}
Employee burnout remains a legitimate concern for organizations because of its links to costly outcomes, including increased absenteeism, turnover, and reduced employee productivity. An emerging stream of research has provided initial evidence that burnout can be highly contagious (i.e., transferable) between employees, suggesting that it may be a meaningful dyadic construct. These initial findings suggest that if organizations do not undertake efforts to curb burnout, it could spread among employees and result in detrimental consequences. However, the existing burnout contagion literature has been plagued by methodological problems and has focused primarily on main effects, revealing little about the causal processes underlying dyadic burnout.
\end{abstract}

To date, several scholars have cited the importance of the role of the supervisor in providing employees with key resources enabling them to effectively cope with job demands, thereby reducing the risk of burnout. However, although literature continues to cite the importance of supervisory behavior as a factor contributing to subordinate burnout, a model detailing the role of the supervisor in the subordinate burnout process has yet to be articulated. Drawing on a sample of 103 supervisor-subordinate dyads, this paper articulates and tests a model of dyadic burnout with a specific focus on how supervisor burnout affects subordinate burnout, both directly and through their leader-member exchange relationship. Results and implications for theory and practice are discussed.

Keywords: Burnout; Leader; Supervisor; Subordinate

\section{INTRODUCTION}

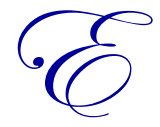

mployee burnout is a legitimate concern for organizations because of its links to costly outcomes, including increased absenteeism, turnover, and reduced employee productivity (Cordes \& Dougherty, 1993), among others. Consequently, burnout research has a long history in applied psychology, with decades of research and hundreds of studies examining its antecedents and consequences (Cordes \& Dougherty, 1993; Shirom, 1989; Taris, 2006). The vast majority of existing burnout research has been conducted at the individual level of analysis only, linking individual employee burnout to individual outcomes (Ashforth, 1993; 1996; Chullen, Dunford, Angermeier, Boss, \& Boss, 2010).

However, an emerging stream of research has provided initial evidence that burnout can be highly contagious (i.e., transferable) between employees, suggesting that it may be a meaningful dyadic construct (Bakker $\&$ Schaufeli, 2000). These initial findings suggest that if organizations do not undertake efforts to curb burnout, it could spread among employees and result in detrimental consequences. Unfortunately, the existing burnout contagion literature (Bakker, Demerouti, \& Schaufeli, 2003; Bakker, LeBlanc, \& Schaufeli, 2005; Bakker, Schaufeli, Sixma, \& Bosveld, 2001; Bakker, Van Emmerik \& Euwema, 2006), has been plagued by methodological problems and has focused primarily on main effects, revealing little about the causal processes underlying dyadic burnout. 
Recently, Dunford, Shipp, Boss, Angermeier, and Boss (2012) described how burnout differed in its pattern of change over time as a function of career transition. Consistent with other scholars (e.g., Feldman, 1976; Feldman, 1981; Feldman \& Brett, 1983; Pinder \& Schroeder, 1987), their work cited the importance of the role of the supervisor in providing employees with key resources enabling them to effectively cope with job demands, thereby reducing the risk of burnout. However, although literature continues to cite the importance of supervisory behavior as a factor contributing to subordinate burnout, a model detailing the role of the supervisor in the subordinate burnout process has yet to be articulated. Understanding the role of the supervisor in the subordinate burnout process is critical because as it may help organizations develop leadership practices that reduce and eliminate burnout's prevalence in the workplace.

Thus, although there is emerging evidence that burnout is contagious and that burnout is a meaningful dyadic construct, the literature has been virtually silent on the process that underlies dyadic burnout. This is especially surprising as supervisors are frequently referenced in discussions of subordinate burnout. Accordingly, the purpose of this paper is to advance the burnout literature by examining a model of dyadic burnout with a specific focus on how supervisor burnout affects subordinate burnout.

\section{THEORY \& HYPOTHESES}

Emotional contagion theory (Hatfield, Cacioppo, \& Rapson, 1994) articulates one way in which supervisors may influence the burnout contagion process. Hatfield et al. (1994, p. 5) defined emotional contagion as "The tendency to automatically mimic and synchronize facial expressions, vocalizations, postures, and movements with those of another person and, consequently, to converge emotionally." Research supports this conclusion, showing that teammates indeed transmit attitudes such as burnout to one another in such a manner that the team itself may become "burned out" (Bakker et al., 2003; Bakker et al., 2005). If teammates are capable of transmitting burnout to one another, it follows that supervisory burnout should too influence subordinate burnout via the emotional contagion process.

Additionally, supervisor burnout may also affect subordinate burnout indirectly. Two theoretical frameworks - conservation of resources (COR) theory (Hobfoll, 1989) and leader-member exchange (LMX) theory (Graen \& Scandura, 1987; Liden \& Maslyn, 1998) - offer complimentary insights into the process leading to subordinate burnout.

COR theory describes how critical job resources and demands affect employee burnout. Due to their unique positions within organizations, supervisors may influence critical job resources of their subordinates which have important implications for subordinate burnout. Similarly, Blau contended that social exchange relationships develop from "favors that create diffuse future obligations, not precisely defined ones, and the nature of the return cannot be bargained about but must be left to the discretion of the one who makes it" (1964, p. 93). Leader-member exchange (LMX) theory refers to the dyadic social exchange relationship that exists between supervisors and subordinates and discusses how supervisors exchange important resources with subordinates that assist them in completing their work. Please see Figure 1 for an overall theoretical model representing all study variables.

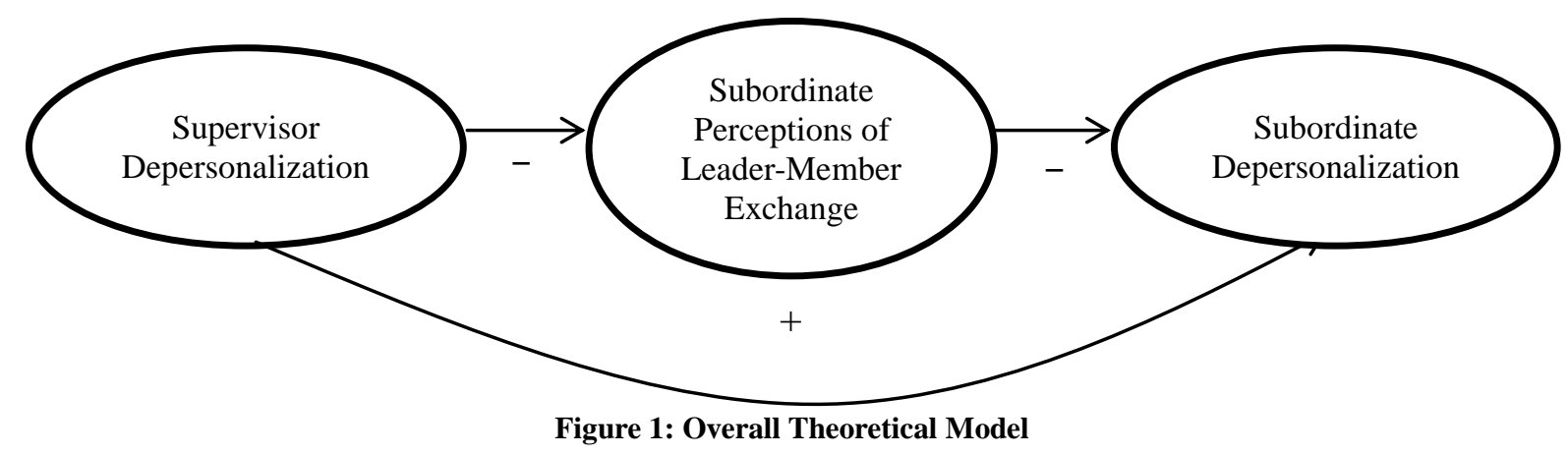

Copyright by author(s); CC-BY 


\section{Dimensions of Burnout}

The term "burnout" has been around since the early 1970s but became mainstream in scholarly and management circles by the mid-1980s when more than 300 articles and over 12 books were published on the topic (Shirom, 1989). Following influential work by Maslach and colleagues (Maslach, 1982; Maslach \& Jackson, 1981; Pines \& Maslach, 1978), burnout is widely considered to be a multi-dimensional construct consisting of three related, but distinct, sub-dimensions. First, emotional exhaustion refers to a "lack of energy and a feeling that one's emotional resources are used up" (Cordes \& Dougherty, 1993). Second, depersonalization refers to the development of negative, cynical attitudes about one's work, coworkers, and customers (Jackson, Turner, \& Brief, 1987) and is considered a coping mechanism wherein employees treat others around them as objects rather than people (Lee \& Ashforth, 1996). Finally, reduced personal accomplishment refers to an individual's feelings of diminished ability in accomplishing tasks related to his or her job (Halbesleben \& Bowler, 2005).

This paper focuses on the depersonalization dimension of burnout. Depersonalization was chosen because it has been shown to have direct links to job performance (Lee \& Ashforth, 1996) and because it has been shown to be highly contagious between employees (Cherniss, 1980; Edelwich \& Brodsky, 1980; Golembiewski \& Munzenrider, 1982).

\section{Emotional Contagion}

There are two obvious ways that burnout may become shared among employees. First, employees could respond similarly to shared events and therefore end up feeling the same way. In this instance, employees are exposed to a particular combination of job demands and resources. Accordingly, the work environment may be responsible for employee burnout. The second way employees may share collective feelings of burnout is if employees affect each other's moods such that their moods converge (Totterdell, 2000). In this example, an employee may begin to feel emotionally drained at work, feel personally ineffective on the job, and begin to express cynical and callous attitudes toward others. In doing so, coworkers may begin to "catch" these attitudes and feelings and experience them themselves. This process is referred to as emotional contagion. Research by Bakker et al. (2006) and Chullen (2014) provide support for the latter, finding evidence for shared feelings of burnout among employees even after controlling for conditions of the work environment.

As previously noted, emotional contagion is defined as "The tendency to automatically mimic and synchronize facial expressions, vocalizations, postures, and movements with those of another person and, consequently, to converge emotionally" (Haftield et al., 1994, p. 5). Several studies support this prediction, showing that individuals nonconsciously mimic the physical expressions and behaviors of others during conversation (Bavelas, Black, Lemery, \& Mullett, 1987; Bernieri, Reznick, \& Rosenthal, 1988).

Researchers have also convincingly argued that individuals may "catch" the emotions of others through a conscious cognitive process by "attending" to the emotions of others (Bakker et al., 2003). In this instance, an individual may identify or empathize with another and, through this process, may recall similar experiences in which they felt the same way. In so doing, the individual may also feel similar emotions and their mood will begin to converge.

A growing body of literature in applied psychology demonstrates that colleagues operate as role models in the workplace, whose symptoms are replicated through the process of emotional contagion (Barger \& Grandey, 2006; Bono \& Ilies, 2006; Ilies, Wagner, \& Morgesen, 2007). For example, in an investigation of teachers, Bakker and Schaufeli (2000) reported that employees who frequently engaged in discussion with burned out colleagues about problematic students displayed higher tendencies of catching their colleagues' negative attitudes. Similarly, Bakker et al. (2001) found that through either conscious or unconscious induction, human service professionals "caught" the negative, cynical attitudes of their burned out colleagues.

Hatfield et al. (1994) argued that individuals are more likely to communicate their feelings when they believe they have the freedom to do so and that they are more likely to catch the feelings of others when they attend to and are able to read others' feelings. Accordingly, supervisors appear most prominently to act as transmitters of 
burnout while subordinates appear more likely to be receivers of burnout. As supervisors control employees' time, resources, and interactions, more ample opportunities exist for them to express and transmit their burnout. Furthermore, subordinates are more likely to attend to their supervisors' burnout because they depend more on their supervisor than vice versa. Indeed, Lewis (2000) found that subordinates are able to ascertain their supervisors' affective displays and that individuals of lower status more often catch the feelings of individuals of higher status than the reverse (Anderson, Keltner, \& John, 2003). Therefore, drawing on emotional contagion theory, it is hypothesized:

Hypothesis 1: Supervisor depersonalization is positively related to subordinate depersonalization.

\section{Leader-Member Exchange (LMX)}

LMX theory proposes that, over time, leaders develop differentiated relationships with their subordinates and that the quality of these relationships has important implications for subordinate attitudes and behaviors (Gerstner \& Day, 1997; Liden, Sparrowe, \& Wayne, 1997; Sparrowe \& Liden, 1997). These emerging relationships can be characterized into either high or low-quality exchanges.

High quality LMX relationships are characterized by the greater negotiating latitude that supervisors extend to subordinates (Graen \& Scandura, 1987) as well as the mutual respect that supervisors and subordinates share for one another (Liden \& Maslyn, 1998). High quality LMX supervisors provide subordinates with social support through extensive attention and interaction that conveys both interpersonal concern and career-focused guidance. Subordinates who receive such attention should experience greater organizational socialization and subsequently less job burnout. Conversely, low-quality LMX relationships are characterized by lower levels of negotiating latitude and mutual respect (Liden \& Maslyn, 1998). They have been associated with dominance-like communication (Fairhurst, Roger, \& Sarr, 1987) and autocratic decision-making (Scandura, Graen, \& Novak, 1986). This high quality/low quality exchange distinction has important implications for burnout.

\section{Conservation of Resources (COR)}

COR theory proposes that individuals reduce their efforts and level of performance in response to ongoing, seemingly insurmountable job demands, particularly when they perceive that compensating resources to cope with those demands are diminishing and are not likely to be replenished (Hobfoll, 1989; Kay, Gaucher, Napier, Callan, \& Laurin, 2008). Stated more directly, an employee's decision to invest resources in their work may be contingent upon the extent to which they perceive they will be able to obtain additional resources in the work environment that can replenish their resource investment.

Specifically, this paper is referencing invested resources which may be reciprocated via social exchange relationships with one's supervisor (Dormann \& Zapf, 1999; Muraven, Tice, \& Baumeister, 1998). Hobfoll (1989) noted that an individual may experience stress during circumstances in which a lack of resource gain follows an investment of resources. Resources that are reciprocated offset and replenish those resources which have been invested and can include support and communication (Halbesleben, 2006; Karasek, Triantis, \& Chaudhry, 1982). These resources have the ability to recharge an employee's exhausted energy and emotional resources, uplift negative, cynical attitudes, and/or restore confidence and feelings of accomplishment in order to reduce the negative effects associated with burnout (Dormann \& Zapf, 1999; Muraven et al., 1998). However, the absence of these resources activates an energy depletion process whereby an employee's sustained increase in efforts to meet perceived job demands is met with an increase in compensatory psychological and physiological costs that drain the employee's energy. This depletion of energy and increased stress from responding to demands gradually leads employees to feel used up and burned out over time.

Supervisors' expressions of cynical attitudes (i.e., depersonalization) toward others are expected to directly affect subordinates' perceptions of their leader-member exchange relationship. As supervisors begin to experience burnout depersonalization, attitudes will manifest themselves in negative behavior, such as criticism of others (Dean Jr., Brandes, \& Dharwadkar, 1998), that will worsen over time. These behaviors are associated with less emotional attachment to others (Naus, van Iterson, \& Roe, 2007). Expressions of negative emotions have been regarded to 
represent poor judgment on the part of the leader, signifying a lack of concern for employee and customer wellbeing (Kirkpatrick \& Locke, 1991). Over time, as supervisors become cynical, subordinates should begin perceiving that investments of resources are likely to be followed by a lack of resource gain and that their supervisor lacks concern for them (also essential to the leader-member exchange relationship), resulting in diminished perceptions of their LMX relationship. Similarly, supervisors experiencing depersonalization should begin to conserve their own resources in an effort to reduce furthering their own burnout and withdraw from investing in the same way with their subordinates, thus resulting in lower quality LMX relationships. Supporting this argument, both field and experimental studies have found that people begin to reduce their responsiveness and availability toward others as they start to feel burned out (Baumeister, Bratslavsky, Muraven, \& Tice, 1998; Repetti, 1989). Therefore, drawing on COR and LMX theory, it is hypothesized:

Hypothesis 2: Supervisor depersonalization is negatively related to subordinate perceptions of LMX.

Subordinates sharing high quality exchanges with their supervisors receive regular resources, including increased communication, increased negotiating latitude, and greater organizational socialization which assists in clearer expectations, thus keeping burnout at bay. In contrast, subordinates sharing low quality exchanges with their supervisors do not receive regular resources and witness decreased communication, decreased negotiating latitude, and lower organizational socialization, resulting in unclear expectations. Over time, because subordinates in the latter position must face their daily environment absent of these important resources, they should begin to experience burnout (Astrom, Nilsson, Norgerg, Sandman, \& Winblad, 1990; Jackson et al., 1987; Leiter, 1989). Therefore, drawing on COR and LMX theory, it is hypothesized:

Hypothesis 3: Subordinate perceptions of LMX are negatively related to subordinate depersonalization.

Drawing on the discussion outlined above related to emotional contagion theory, COR theory, and LMX theory, a mediated relationship can be inferred regarding the linkages between supervisor depersonalization, subordinate perceptions of LMX, and subordinate depersonalization.

Hypothesis 4: Subordinate perceptions of LMX partially mediate the relationship between supervisor depersonalization and subordinate depersonalization.

\section{METHODS}

Participants for this study were drawn from a mental and behavioral health services organization employing approximately 460 total personnel (of which 140 served in a supervisory capacity), located in the Midwestern United States. Overall, respondents from this organization were, on average, 37.77 years of age, had worked in their current organization for 5.33 years, had worked for their present immediate supervisor for 2.85 years, and were $81 \%$ female (19\% male).

Data for this study were collected through an employee opinion survey at three time intervals. Each survey was administered online over a one-week period during which all employees were solicited to participate. The survey at Time 1 was followed by a two-month down period prior to the opening of the survey at Time 2. Further, the survey at Time 2 was followed by a one-month down period prior to the opening of the survey at Time 3 .

Data related to control variables (i.e., age, gender, organizational tenure, tenure with supervisor, subordinate role conflict, and subordinate role ambiguity) and data related to supervisor depersonalization were collected from at Time 1. Data related to subordinate perceptions of LMX were collected at Time 2 and data related to subordinate depersonalization were collected at Time 3. A coding system was used to match supervisor and subordinate responses. The Director of Human Resources confirmed all employees within this organization maintain "regular, daily face-to-face interaction" with their supervisor.

A total of 247 employees responded to the survey administered at Time 1 (54\% initial overall response rate). Of the respondents at Time 1, 127 of them served in a supervisory capacity ( $91 \%$ initial supervisor response rate) whereas 120 respondents did not serve in a supervisory capacity ( $40 \%$ initial subordinate response rate). Of the 
120 subordinate respondents who participated at Time 1, 109 responded to and completed the remaining surveys at both Times 2 and 3. Of the final 109 subordinate respondents who participated in all three time waves of the study, six did not have a supervisor who participated in the study. Similarly, of the 127 supervisor respondents from Time 1, 26 did not have a subordinate who participated in the study. These numbers represent a final overall employee useable response rate of $45 \%$, an $74 \%$ final supervisor useable response rate, and a $29 \%$ final subordinate useable response rate. Each supervisor had only one subordinate who participated in all three waves of data collection in this study. Therefore, multilevel analysis of data was not appropriate. Accordingly, a total of 103 supervisorsubordinate dyads (1 supervisor: 1subordinate) served as the data sample for this study.

\section{Measures}

Burnout

Burnout was measured using the depersonalization subscale from the Maslach Burnout Inventory (MBI; Maslach \& Jackson, 1981) consisting of five items. Sample items included "I feel I treat some people at work as if they were impersonal 'objects" and "I've become more callous toward people since I took this job." Items were assessed on a 7-point Likert scale $(1=$ Strongly Disagree to $7=$ Strongly Agree $)$. This measure demonstrated satisfactory reliability for both supervisors at Time $1(.81)$ and subordinates at Time $3(\alpha=.83)$, respectively.

\section{Leader-Member Exchange}

Subordinate perceptions of LMX were measured using Graen \& Scandura's (1987) seven-item scale. Sample items included "My working relationship with my supervisor is very effective" and "My supervisor understands my job problems and needs." Items were assessed on a 7-point Likert scale ( 1 = Strongly Disagree to 7 $=$ Strongly Agree). This measure demonstrated satisfactory reliability for subordinates at Time $2(\alpha=.92)$.

\section{Controls}

Prior research indicates that burnout is associated with age (e.g., Maslach \& Jackson, 1981, 1985), gender (e.g., Maslach \& Jackson, 1981, 1985; Pretty, McCarthy, \& Catano, 1992), and organizational tenure (Burke, 1989), as well as environmental factors of the work setting (Pines \& Maslach, 1978; Maslach \& Pines, 1977), including role conflict and role ambiguity. Additionally, LMX quality has been found to be related to subordinate demographic characteristics, including age, gender, and organizational tenure (Green, Anderson, \& Shivers, 1996; Liden, Wayne, \& Stillwell, 1993). Accordingly, this study controlled for employee age, gender, organizational tenure, subordinate role conflict, and subordinate role ambiguity, as well as tenure with current supervisor, inasmuch as these variables may have been related to the supervisor depersonalization, subordinate perceptions of LMX, and subordinate depersonalization.

\section{RESULTS}

See Table 1 in the Appendix which illustrates the means, standard deviations, correlations, and reliability estimates (Cronbach alphas) for all study variables.

Hypotheses were tested using structural equation modeling (IBM SPSS Amos Ver. 20). Prior to testing hypothesized relationships, a series of confirmatory factor analyses was performed to determine the construct validity of study measures. Table 2 (see Appendix) illustrates the fit indices for the measurement model contrasted with four alternative models (Anderson \& Gerbing, 1988).

As depicted in Table 2, the three-factor measurement model produced the best fit for the data: comparative fit index $=.95$, standardized root mean square residual $=.03$, and root mean square error of approximation $90 \%$ confidence interval $=.05, .06$. In order to allay concerns related to common method bias, each set of indicators was loaded onto their latent variables; then all indicators were loaded onto a fourth, common method latent variable. This four-factor model did not converge. Additionally, a Harman single-factor test (see Podsakoff, MacKenzie, Lee, \& Podsakoff, 2003) was performed and results showed that items did not significantly load onto a single factor. 
Accordingly, it was determined that common method bias was not a serious concern in this study's analysis. Following this, the structural equation analysis was performed. All path coefficients were estimated while simultaneously controlling for employee age, gender, organizational tenure, tenure with current supervisor, subordinate role conflict, and subordinate role ambiguity. To test the proposed model, this study followed the analytical approach outlined by Preacher and Hayes (2004) and Shrout and Bolger (2002). This mediation approach directly tests the indirect effect between the independent and dependent variables through the mediator via a bootstrapping procedure (Efron \& Tibshirani, 1993; Mooney \& Duval, 1993) while addressing some of the shortcomings associated with the Sobel test (Preacher \& Hayes, 2004; Shrout \& Bolger, 2002). The structural model showed an acceptable fit: $\chi^{2}=152.52$, comparative fit index $=.95$, standardized root mean square residual $=$ .03 , and root mean square error of approximation $90 \%$ confidence interval $=.05, .06$.

Table 3 (see Appendix) illustrates the path coefficients and indirect effects for the mediation model along with the symmetric and $95 \%$ bias corrected bootstrapped confidence intervals for the path estimates. Figure 2 also displays the estimates from the structural path coefficients.

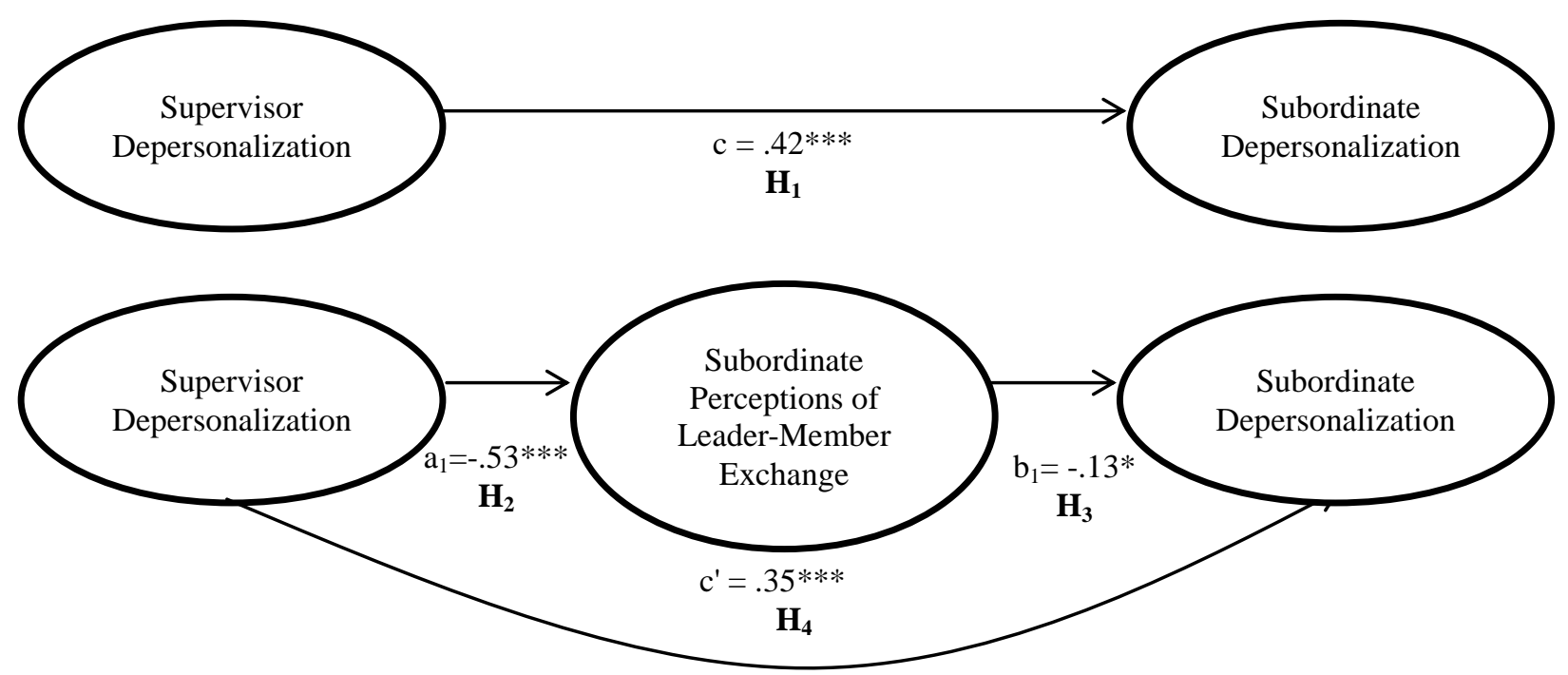

\begin{tabular}{|l|c|c|c|c|c|}
\hline & Model 1 & & Model 2 & Model 3 \\
\hline$\Delta R^{2}$ & .48 & & & .09 & .05 \\
\hline Total $R^{2}$ & .48 & & & .57 & \\
\hline Note: Adapted from "Mediation and the Estimation of Indirect Effects in Political Communication Research" by A. F. Hayes, K. J. Preacher, \\
and T. A. Myers, 2011, The Sourcebook for Political Communication Research: Methods, Measures, and Analytical Techniques, by E. P. Bucy \\
and R. L. Holbert, New York, NY: Routledge. \\
$N=103 . \dagger p<.10, * p<.05, * * p<.01, * * * p<.001$ \\
Model 1: Control Variables \\
Model 2: Control Variables + Supervisor Depersonalization \\
Model 3: Control Variables + Supervisor Depersonalization + Subordinate Perceptions of LMX
\end{tabular}

Figure 2: Mediation Model Results

As predicted in Hypothesis 1, supervisor depersonalization was positively related to subordinate depersonalization. Hypothesis 2; i.e., supervisor depersonalization, is negatively related to subordinate perceptions of leader-member exchange, was also found to be supported. Hypothesis 3 stated that subordinate perceptions of leader-member exchange are negatively related to subordinate depersonalization. Results supported this prediction. Lastly, results from Hypothesis 4 found that subordinate perceptions of leader-member exchange partially mediated the relationship between supervisor depersonalization and subordinate depersonalization. Additionally, although not included in Table 3 for parsimony, among control variables, only role conflict (est. $=.80, \mathrm{t}=6.83, \mathrm{p}<.001$ ) and role ambiguity (est. $=.26, \mathrm{t}=2.10, \mathrm{p}<.05$ ) were found to be related to subordinate depersonalization. 


\section{DISCUSSION}

\section{Implications for Theory, Research, and Practice}

This study contributes to the burnout literature in several ways. First, results suggest that supervisor burnout (particularly supervisor depersonalization) plays a critical role in the development of subordinate burnout (particularly supervisor depersonalization). More specifically, as supervisors experience depersonalization, they affect subordinate depersonalization both directly (through emotional contagion) and indirectly (through their leader-member exchange relationship). To date, the vast majority of research has investigated burnout as a reaction to chronic or ongoing demands from the job (Hobfoll \& Shirom, 1993; Westman \& Eden, 1997; Zohar, 1997). This study highlights the role of the supervisor in influencing subordinate burnout after controlling for job demands in the work environment.

Additionally, this study contributes to the author's understanding concerning the emotional contagion process and burnout within a leadership context. Although various moods and emotions have received attention (Cherulnik, Donley, Wiewel, \& Miller 2001; Lewis, 2000; Sy, Cote', \& Saavedra, 2005), this study is the first to address burnout. Findings suggest that supervisors act as highly salient organizational members that transmit their depersonalization via emotional contagion to their subordinates.

Third, this study contributes to the literature by identifying subordinate perceptions of leader-member exchange as an important mediating mechanism within the supervisor burnout to subordinate burnout relationship. To date, the existing burnout contagion literature has focused primarily on main effects, revealing little about the causal processes underlying dyadic burnout.

Similarly, although not explicitly concerned with burnout, most literature examining the effects of supervisor moods and emotions on subordinates has also focused almost exclusively on the direct relationship while ignoring potentially important mediators. Commenting on the current state of the literature in this regard, Sy et al. (2005; p. 303) noted, "At this point, however, we cannot make definitive statements about the precise mechanisms that underlie the effects of the mood of the leader." This research study provides support that subordinate perceptions of leader-member exchange mediate the relationship between supervisor depersonalization and subordinate depersonalization. Findings reveal a deeper understanding of the processes leading from supervisor burnout to subordinate burnout.

Additionally, this study contributes to management practice. First, supervisors must understand that their own affective states have important implications for those of their employees. This study found that supervisors who expressed negative, cynical attitudes about their work and others affected subordinates such that their moods converged. Accordingly, it would be beneficial for supervisors to learn how to regulate and suppress their displays of burnout. Supervisors who are skilled at regulation should be more effective in minimizing emotional contagion that may hinder employee performance while facilitating emotional contagion that may improve employee performance during the relationship.

Second, results suggest supervisors are a key source of employee burnout. Organizations should carefully monitor burnout among supervisors and proactively take steps to reduce and eliminate its occurrence. By preventing the onset of burnout in supervisors, organizations can minimize its negative effects on the supervisor-subordinate relationship, preventing it from spreading, over time, from the upper management down into the workforce. Organizations can assess burnout among supervisors through regular employee well-being surveys. Further, training in cognitive and behavioral strategies (see Schaufeli \& Enzmann, 1998, for an overview) may assist in reducing and eliminating burnout in supervisors.

Third, this study highlights the role of high-quality exchanges between supervisors and subordinates. Results suggest that diminished perceptions of leader-member exchange are associated with increased employee burnout. Supervisors may need guidance on how to cultivate high-quality exchanges with subordinates over time, including communicating important job-related information and providing greater socialization to their employees. 


\section{LIMITATIONS \& SUGGESTIONS FOR FUTURE RESEARCH}

First, this study drew from a sample in the mental health services industry. As this sample is not representative of the population of organizations in the world at large, results may not be generalizable to other contexts. Future studies should explore the generalizability of these findings by conducting additional research across an array of different organizations in many different areas of the world. However, healthcare settings, such as the mental health services organization surveyed in this study, do provide a fitting context in which to study burnout. Healthcare professionals have historically been faced with challenging workloads and extensive responsibilities. This research study focused, in part, on subordinate burnout as a function of supervisor burnout. Focusing on healthcare settings in particular, other workplace conditions provide fruitful avenues for exploration on employee burnout and how it changes over time. For example, patients and their family members dealing with illness and perhaps ultimately death, may be unable to regulate their expressions of sadness or anger when interacting with healthcare providers (Demerouti, Bakker, Nachreiner, \& Schaufeli, 2001; Leiter \& Maslach, 1988). Therefore, through emotional contagion processes, patients and their family members may transmit their emotions directly to those healthcare providers assisting them.

Second, this study is limited in that it focuses on the direct and indirect effects of supervisor burnout on subordinate burnout without investigating potentially important moderating influences. Future research should explore how individual differences influence the supervisor to subordinate burnout relationship. For example, facial expressiveness serves as an individual difference variable highly relevant to future research on emotional contagion. Ample evidence exists to demonstrate that individuals' affective states are influenced by the physiological feedback they receive from those surrounding them in their environment. Within the context of burnout, this dialogue suggests that the facial feedback subordinates receive from their supervisors may act as an important determinant of the degree to which emotional contagion occurs. Specifically, the facial expressiveness of a supervisor may exacerbate the affective state being transferred during the emotional contagion process. Hatfield et al. (1994; p. 138) discussed transmitters as those, "who by their innate bodily circuitry, transmit their emotions to others." Accordingly, this can be assessed via the facial expressiveness scale (Klein \& Cacioppo, 1993).

Third, this study is limited in that it focuses on directional burnout from the top-down; i.e., supervisor-tosubordinate burnout rather than subordinate-to-supervisor burnout. However, it is possible that subordinates may also transfer their burnout to supervisors. Research by Barsade (2002) supports this idea. She found that participants in experiments may also influence the moods of individuals of higher status. Future studies should determine if and how subordinates influence supervisor burnout and what, if any, moderating and mediating variables are critical to that relationship.

Lastly, following recommendations by Podsakoff et al. (2003), this study collected measures of interest from different sources across separate time periods. This practice strengthened study design, allowing more concrete conclusions to be drawn from its analyses while reducing the possibility of common method variance. Despite these strengths, this study's design did not capture the day-to-day experiences of respondents - something which may be critical to understanding burnout, especially in organizational newcomers. Thus, future research studies investigating burnout should consider measuring burnout with diaries.

\section{CONCLUSION}

The present study highlights the relationship between supervisor burnout (particularly supervisor depersonalization) and subordinate burnout (particularly subordinate depersonalization). As burnout continues to plague organizations, understanding its origins and how it manifests itself among and between employees is of great importance. The present study offers some valuable insights into the burnout process by detailing the role of emotional contagion and leader-member exchange between supervisors and subordinates.

\section{AUTHOR INFORMATION}

Dr. Cody Logan Chullen is an Assistant Professor of Management in the College of Business at East Carolina University. He principally teaches managerial negotiation at the undergraduate level, both face-to-face and online. His primary research interests include leadership processes (e.g., LMX) and occupational stress, strain, and well- 
being (e.g., burnout), with supporting interests in legal issues in human resource management (e.g., EEOC complaints \& lawsuits) and workplace issues in healthcare (e.g., deviant behavior \& involuntary turnover). He earned his Ph.D. in Organizational Behavior and Human Resource Management from the Krannert Graduate School of Management at Purdue University. E-mail: chullenc@ecu.edu

\section{REFERENCES}

1. Anderson, C., Keltner, D., \& John, O. P. (2003). Emotional convergence in close relationships. Journal of Personality and Social Psychology, 84, 1054-1068.

2. Astrom, S., Nilsson, M., Norgerg, A., Sandman, P. O., \& Winblad, B. (1990). Staff burnout in dementia care: Relations to empathy and attitudes. International Journal of Nursing Studies, 28, 65-77.

3. Bakker, A. B., Demerouti, E., \& Schaufeli, W. B. (2003). The socially induced burnout model. In S. P. Shohov (Ed.), Advances in psychology research (Vol. 25). New York: Nova Science Publishers.

4. Bakker, A. B., Le Blanc, P. M., \& Schaufeli, W. B. (2005). Burnout contagion among nurses who work at intensive care units. Journal of Advanced Nursing, 51, 276-287.

5. Bakker, A. B., \& Schaufeli, W. B. (2000). Burnout contagion processes among teachers. Journal of Applied Social Psychology, 30, 2289-2308.

6. Bakker, A. B., Schaufeli,W. B., Sixma, H. J., Bosveld,W., \& van Dierendonck, D. (2000). Patient demands, lack of reciprocity, and burnout: A five-year longitudinal study among general practitioners. Journal of Organizational Behavior, 21, 425-441.

7. Bakker, A. B., Van Emmerik, J. H., \& Euwema, M. E. (2006). Crossover of burnout and engagement in work teams. Work \& Occupations, 33, 1-26.

8. Barger, P. B., \& Grandey, A. A. (2006). Service with a smile and encounter satisfaction: Emotional contagion and appraisal mechanisms. Academy of Management Journal, 49, 1229-1238.

9. Barsade, S. G. (2002). The ripple effect: Emotional contagion and its influence on group behavior. Administrative Science Quarterly, 47, 644-675.

10. Bavelas, J. B., Black, A., Lemery, C. R., \& Mullett, J. (1987). Motor mimicry as primitive empathy. In N. Eisenberg \& J. Strayer (Eds.), Empathy and its development (pp. 317-338). New York: Cambridge University Press.

11. Baumeister, R. F., Bratslavsky, E., Muraven, M., \& Tice, D. M. (1998). Ego depletion: Is the active self a limited resource? Journal of Personality and Social Psychology, 74, 1252-1265.

12. Bernieri, F. J., Reznick, J. S., \& Rosenthal, R. (1988). Synchrony, pseudosynchrony, and dissynchrony: Measuring the entrainment process in mother-infant interactions. Journal of Personality and Social Psychology, 54, 1242-1253.

13. Blau, P. (1964). Exchange and power in social life. New York: Wiley.

14. Bono, J. E., \& Ilies, R. (2006). Charisma, positive emotions and mood contagion. The Leadership Quarterly, 17, 317-334.

15. Cherniss, C. (1980). Professional burnout in human service organizations. New York: Praeger.

16. Cordes C. L., \& Dougherty, T. W. (1993). A review and integration of research on job burnout. Academy of Management Review, 18, 621-656.

17. Cherulnik, P. D., Donley, K. A.,Wiewel, T. S. R., \& Miller, S. R. (2001). Charisma is contagious: The effect of leaders' charisma on observers' affect. Journal of Applied Social Psychology, 31, 2149-2159.

18. Chullen, C. L. (2014). Burnout contagion in supervisor-subodinate dyads. Business and Management Research, 3(2), 67-80.

19. Chullen, C. L., Dunford, B. B., Angermeier, I., Boss, R. W., \& Boss, A. D. (2010). Minimizing deviant behavior in healthcare organizations: The effects of supportive leadership and job design. Journal of Healthcare Management, 55(6), 381-397.

20. Dean Jr, J. W., Brandes, P., \& Dharwadkar, R. (1998). Organizational cynicism. Academy of Management Review, 23, 341-52.

21. Demerouti, E., Bakker, A. B., Nachreiner, F., \& Schaufeli, W. B. (2001). The job demands-resources model. Journal of Applied Psychology, 86, 499-512.

22. Dormann, C., \& Zapf, D. (1999). Social support, social stressors at work, and depressive symptoms: Testing for main and moderating effects with structural equations in a three-wave longitudinal study. Journal of Applied Psychology, 84, 874-884. 
23. Dunford, B. B., Shipp, A. J., Boss, R. W., Angermeier, I., \& Boss, A. D. (2012). Is burnout static or dynamic? A career transition perspective of employee burnout trajectories. Journal of Applied Psychology, 97(3), 637-650.

24. Edelwich, J., \& Brodsky, A. (1980). Burnout: Stages of dillusionment in the helping professions. New York: Human Sciences Press.

25. Efron, B., \& Tibshirani, R. 1993. An introduction to the bootstrap. New York: Chapman \& Hall.

26. Fairhurst, G. T., Roger, L. E., \& Sarr, R. A. (1987). Manager-subordinate control patterns and judgments about the relationship. In M. McLaughlin (Ed.), Communication yearbook (pp. 395-415). Beverly Hills, CA: Sage.

27. Feldman, D. C. (1976). A contingency theory of socialization. Administrative Science Quarterly, 21, 433452.

28. Feldman, D. C. (1981). The multiple socialization of organizational members. Academy of Management Review, 6, 309-318.

29. Feldman, D. C., \& Brett, J. (1983). Coping with new jobs: A comparative study of new hires and job changers. Academy of Management Journal, 26, 258-272.

30. Gerstner, C. R., \& Day, D. V. (1997). Meta-analytic review of leader-member exchange theory: Correlates and construct issues. Journal of Applied Psychology, 82, 827-844.

31. Golembiewski, R. T., Munzenrider, R. F., \& Stevenson, J. G. (1986). Stress in organizations: Towards a phase model of burnout. New York: Praeger.

32. Graen, G. B., \& Scandura, T. A. (1987). Toward a psychology of dyadic organizing. Research in Organizational Behavior, 9, 175-208.

33. Green, S. G., Anderson, S. A., \& Shivers, S. L. (1996). Demographic and organizational influences on leader-member exchange and related work attitudes. Organizational Behavior and Human Decision Processes, 66, 203-214.

34. Halbesleben, J. R. B., \& Bowler, W. M. (2007). Emotional exhaustion and job performance: The mediating role of motivation. Journal of Applied Psychology, 92, 93-106.

35. Hatfield E., Cacioppo, J. T. \& Rapson, R. L. (1994). Emotional contagion. Cambridge University Press, New York.

36. Hobfoll, S. E. (1989). Conservation of resource: a new attempt at conceptualizing stress. American Psychologist, 44(3), 513-24.

37. Hobfoll, S. E., \& Shirom, A. (1993). Stress and burnout in the workplace. In R. Golembiewski (Ed.), Handbook of organizational behavior (pp. 41-60). New York: Marcel Dekker.

38. Ilies, R., Wagner, D. T., \& Morgesen, F. P (2007). Explaining affective linkages in teams: Individual differences in susceptibility to contagion and individualism-collectivism. Journal of Applied Psychology, 92, 1140-1148.

39. Jackson, S. E., Turner, J. A., \& Brief, A. P. (1987). Correlates of burnout among public service lawyers. Journal of Occupational Behavior, 8, 339-349.

40. Kay, A. C., Gaucher, D., Napier, J. L., Callan, M. J., \& Laurin, K. (2008). God and the government: Testing a compensatory control mechanism for the support of external systems. Journal of Personality and Social Psychology, 95, 18-35.

41. Kirkpatrick, S. A., \& Locke, E. A. (1991). Leadership: do traits matter? Academy of Management Executive, 5, 48-60.

42. Klein, D., \& Cacioppo, J. L. (1993). The facial expressiveness scale and the autonomic reactivity scale. (Unpublished manuscript). Ohio State University, Columbus.

43. Lee, R. T., \& Ashforth, B. E. (1993). A longitudinal study of burnout among supervisors and managers: Comparisons between the Leiter and Maslach (1988) and Golembiewski et al. (1986) models.

Organizational Behavior and Human Decision Processes, 54, 369-398.

44. Lee, R. T., \& Ashforth, B. E. (1996). A meta-analytic examination of the correlates of the three dimensions of job burnout. Journal of Applied Psychology, 81, 123-133.

45. Leiter, M. P. (1989). Conceptual implications of two models of burnout. A response to Golembiewski. Group \& Organization Studies, 14, 15-22.

46. Lewis, K. M. (2000). When leaders display emotion: how followers respond to negative emotional expression of male and female leaders. Journal of Organizational Behavior, 21, 221-234. 
47. Liden, R. C., \& Maslyn, J. M. (1998). Multi-dimensionality of leader-member exchange: An empirical assessment through scale development. Journal of Management, 24, 43-72.

48. Liden, R. C., Sparrowe, R. T., \& Wayne, S. J. (1997). Leader-member exchange theory: The past and potential for the future. Research in Personnel and Human Resources Management, 15, 47-119.

49. Liden, R. C., Wayne, S. J., \& Stillwell, D. (1993). A longitudinal study on the early development of leadermember exchanges. Journal of Applied Psychology, 78, 662-674.

50. Maslach, C., \& Jackson, S. E. (1981). The measurement of experienced burnout. Journal of Occupational Behaviour, 2, 99-113.

51. Maslach, C., \& Jackson, S. E. (1985). The role of sex and family variables in burnout. Sex Roles, 12, 837851.

52. Maslach, C. (1982). Burnout: The cost of caring. Englewood Cliffs, NJ: Prentice Hall.

53. Maslach, C., \& Pines, A. (1977). The burnout syndrome in the day care setting. Child Care Quarterly, 6, 100-113.

54. Mooney, C. Z., \& Duval, R. D. 1993. Bootstrapping. Thousand Oaks, CA: Sage.

55. Muraven, M., Tice, D. M., \& Baumeister, R. F. (1998). Self-control as a limited resource: Regulatory depletion patterns. Journal of Personality and Social Psychology, 74, 774-789.

56. Naus, F., van Iterson, A., \& Roe, R. (2007). Value incongruence, job autonomy, and organization based self-esteem: A self-based perspective on organizational cynicism. European Journal of Work and Organizational Psychology, 16, 195-219.

57. Pinder, C. C., \& Schroeder, K. G. (1987). Personnel transfers and employee development. In K. J. Rowland \& G. R. Ferris (Eds.), Research in personnel and human resource management, Vol. 2 (pp. 187-218).

Greenwich, CT: JAI Press.

58. Pines, A., \& Maslach. C. (1978). Characteristics of staff burnout in mental health settings. Hospital and Community Psychiatry, 29, 233-237.

59. Podsakoff, P. M., MacKenzie, S. M., Lee, J., \& Podsakoff, N. P. (2003). Common method variance in behavioral research: A critical review of the literature and recommended remedies. Journal of Applied Psychology, 88, 879-903.

60. Preacher, K. J., \& Hayes, A. F. (2004). SPSS and SAS procedures for estimating indirect effects in simple mediation models. Behavior Research Methods, Instruments and Computers, 36, 717-731.

61. Pretty, G. M. H., McCarthy, M. E., \& Catano, V. M. (1992). Psychological environments and burnout: Gender considerations within the corporation. Journal of Organizational Behavior, 13, 701-711.

62. Repetti, R. L. (1989). Effects of daily workload on subsequent behavior during marital interaction: The roles of social withdrawal and spouse support. Journal of Personality and Social Psychology, 57, 651-659.

63. Scandura, T. A., Graen, G. B., \& Novak, M. A. (1986). When managers decide not to decide autocratically: An investigation of leader-member exchange and decision influence. Journal of Applied Psychology, 71, 579-584.

64. Schaufeli, W. B., \& Enzmann, D. (1998). The burnout companion to study and research: A critical analysis. London: Taylor \& Francis.

65. Shirom, A. (1989). Burnout in work organizations. Chapter 2, pp 25-48. In C. L Cooper and I. Robertson (Eds.) International Review of Psychology. John Wiley and Sons.

66. Shrout, P. E., \& Bolger, N. (2002). Mediation in experimental and nonexperimental studies: New procedures and recommendations. Psychological Methods, 7, 422-445.

67. Sparrowe, R. T., \& Liden, R. C. (1997). Process and structure in leader-member exchange. Academy of Management Review, 22, 522-552.

68. Sy, T., Cote', S., \& Saavedra, R. (2005). The contagious leader: Impact of the leader's mood on the mood of group members, group affective tone, and group processes. Journal of Applied Psychology, 90, 205-305.

69. Taris, T. W. (2006). Is there a relationship between burnout and objective performance? A critical review of 16 studies. Work and Stress, 20(4), 316-334.

70. Totterdell, P. (2000). Catching moods and hitting runs: Mood linkage and subjective performance in professional sport teams. Journal of Applied Psychology, 85, 848-859.

71. Westman, M., \& Eden, D. (1997). Effects of vacation on job stress and burnout: Relief and fade-out. Journal of Applied Psychology, 82, 516-527.

72. Zohar, D. (1997). Predicting burnout with a hassle-based measure of role demands. Journal of Organizational Behavior, 18(2), 101-115. 


\section{APPENDIX}

Table 1: Means, Standard Deviations, Correlations, and Reliability Estimates for Study Variables

\begin{tabular}{|c|c|c|c|c|c|c|c|c|c|c|c|}
\hline Variable & Mean & s.d. & 1 & 2 & 3 & 4 & 5 & 6 & 7 & 8 & 9 \\
\hline 1. Age ${ }^{1}$ & 37.77 & 8.03 & & & & & & & & & \\
\hline 2. Gender ${ }^{\text {al }}$ & .19 & .39 & .14 & - & & & & & & & \\
\hline 3. Organizational Tenure ${ }^{1}$ & 5.33 & 2.52 & $.44 * *$ & -.08 & - & & & & & & \\
\hline 4. Tenure w/ Supervisor ${ }^{1}$ & 2.85 & 2.14 & .18 & -.01 & $.50^{* *}$ & - & & & & & \\
\hline 5. Subordinate Role Conflict ${ }^{1}$ & 2.76 & .80 & .17 & $-.21 *$ & $.32 * *$ & .10 & $(.84)$ & & & & \\
\hline 6. Subordinate Role Ambiguity ${ }^{1}$ & 4.32 & .70 & -.11 & .01 & -.24 & .00 & $.22 *$ & $(.80)$ & & & \\
\hline 7. Supervisor Depersonalization ${ }^{1}$ & 2.67 & .97 & -.01 & $-.35 * *$ & $.23^{*}$ & .01 & $.30 * *$ & .08 & $(.81)$ & & \\
\hline 8. Subordinate Perceptions of $\mathrm{LMX}^{2}$ & 5.31 & 1.72 & .03 & .05 & -.01 & $.28 * *$ & $-.33 * *$ & $-.23 *$ & $-.35 * *$ & $(.92)$ & \\
\hline 9. Subordinate Depersonalization ${ }^{3}$ & 2.72 & 1.25 & .06 & $-.23^{*}$ & $.20^{*}$ & .08 & $.67 * *$ & $.29 * *$ & $.49 * *$ & $-.45 * *$ & $(.83)$ \\
\hline
\end{tabular}

Note: $N=103$. Scale reliabilities (Cronbach's alpha) are listed on the diagonal. ${ }^{\mathrm{a}}$ Gender is coded as 0 (females) and 1 (males). ${ }^{1}$ collected at Time $1,{ }^{2}$ collected at Time $2,{ }^{3}$ collected at Time $3 . \dagger p<.10,{ }^{*}$ $p<.05, * * p<.01, * * * p<.001$

\begin{tabular}{|c|c|c|c|c|c|c|}
\hline Measurement Model & $d f$ & $\chi^{2}$ & $\chi^{2} / d f$ & CFI & SRMR & RMSEA \\
\hline Single Factor ${ }^{\mathrm{a}}$ & 119 & 2452.09 & 20.60 & .46 & .28 & $.42, .45$ \\
\hline Two Factors ${ }^{b}$ & 118 & 1609.30 & 13.63 & .66 & .23 & $.33, .37$ \\
\hline Two Factors $^{c}$ & 118 & 1609.27 & 13.64 & .66 & .23 & $.34, .37$ \\
\hline Two Factors ${ }^{\mathrm{d}}$ & 118 & 1544.19 & 13.08 & .67 & .18 & $.33, .36$ \\
\hline Three Factors $^{\mathrm{e}}$ & 116 & 152.52 & 1.31 & .95 & .03 & $.05, .06$ \\
\hline
\end{tabular}

Note: $N=103$. CFI = comparative fit index; SRMR = standardized root mean square residual; RMSEA = root mean square error of approximation, $90 \%$ Confidence Interval a All indicators load on a single factor. ${ }^{b}$ Supervisor Depersonalization loads on its respective factor, and Subordinate Perceptions of Leader-Member Exchange and Subordinate Depersonalization load on one factor. ${ }^{\mathrm{c}}$ Subordinate Depersonalization loads on its respective factor, and Subordinate Perceptions of Leader-Member Exchange and Supervisor Depersonalization load on one factor. ${ }^{\mathrm{d} S u b o r d i n a t e ~ P e r c e p t i o n s ~ o f ~ L e a d e r-~}$ Member Exchange loads on its respective factor, and Supervisor Depersonalization and Subordinate Depersonalization load on one factor. ${ }^{\mathrm{e}}$ Supervisor Depersonalization, Subordinate Perceptions of Leader-Member Exchange, and Subordinate Depersonalization all load on their respective factors.

Table 3: Path Coefficients and Indirect Effects for Mediation Model

\begin{tabular}{|c|c|c|c|c|c|}
\hline & \multicolumn{3}{|c|}{ Path Coefficients } & \multicolumn{2}{|r|}{ Indirect Effects } \\
\hline & To Subordinate LMX & $\begin{array}{c}\text { To Subordinate } \\
\text { Depersonalization }\end{array}$ & Estimate & Symmetric $95 \%$ CI & Bias-Corrected Bootstrap $95 \%$ CI \\
\hline Supervisor Depersonalization & $-.53(.17)$ & $35(.10)$ & & & \\
\hline Subordinate Perceptions of LMX & & $-.13(.06)$ & & & \\
\hline Total & & & $.08(.04)$ & $.01, .16$ & $.02, .21$ \\
\hline
\end{tabular}

Communication Research: Methods, Measures, and Analytical Techniques, by E. P. Bucy and R. L. Holbert, New York, NY: Routledge. $N=103$. Bootstrap confidence intervals were constructed using 5000 resamples. Standard errors in parentheses. Total effect (Supervisor Depersonalization $\rightarrow$ Subordinate Depersonalization) $=.42(.10) . \dagger p<.10, * p<.05, * * p<.01, * * * p<.001$ 
NOTES 